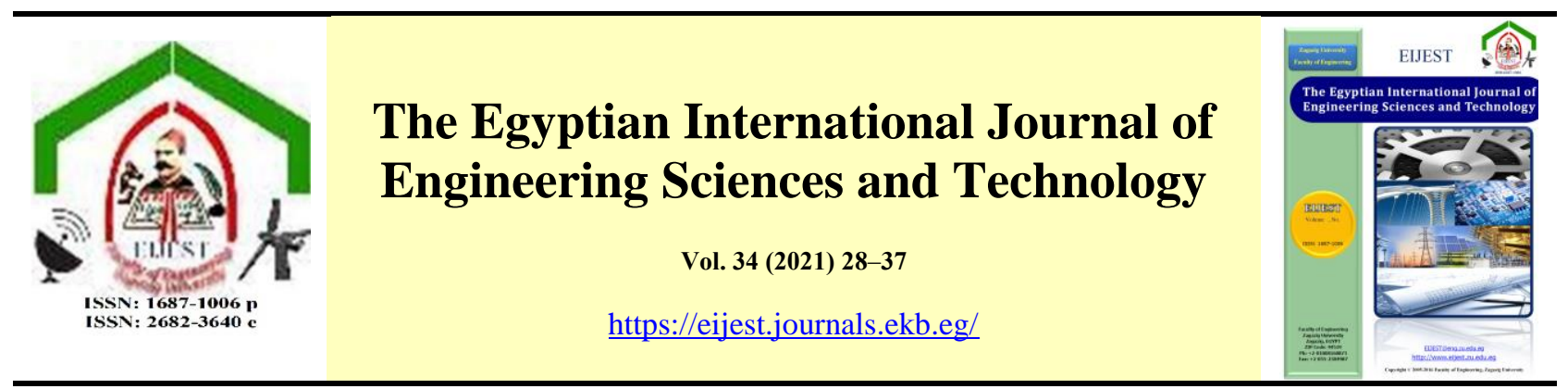

\title{
NUMERICAL ANALYSIS OF FRP REINFORCED FRAMES UNDER CYCLIC LOADING
}

\begin{tabular}{|c|c|}
\hline \multicolumn{2}{|c|}{$\begin{array}{l}\text { Alaa A. Elsisi }{ }^{\mathrm{a}} \text {, Hilal Hassan }{ }^{\mathrm{b}}, \text { Louay Aboul Nour }{ }^{\mathrm{b}} \text {, Asmaa Sobhy }{ }^{\mathrm{c}} * \\
\text { ssistant Research Professor, University of Missouri, USA; on research leave of Zagazig University, Egypt. } \\
{ }^{b} \text { Associate professor Structural Eng. Dept., Faculty of Eng., Zagazig University, Zagazig, Egypt. } \\
{ }^{c} \text { MSc student Structural Engineering, Faculty of Engineering, Zagazig University, Zagazig, Egypt }\end{array}$} \\
\hline ART I CLE INFO & ABSTRACT \\
\hline $\begin{array}{l}\text { Keywords: } \\
\text { Beam-column joint } \\
\text { Cyclic loading } \\
\text { Finite element analysis } \\
\text { Glass fiber reinforced } \\
\text { polymer } \\
\text { Carbon fiber reinforced } \\
\text { polymer } \\
\text { Notations: } \\
\text { GFRP: Glass fiber } \\
\text { reinforced polymer } \\
\text { CFRP: Carbon fiber } \\
\text { reinforced polymer }\end{array}$ & $\begin{array}{l}\text { In this research, three models of beam-column joint have analyzed under reversed } \\
\text { cyclic loading by finite element method using ANSYS software. The first model } \\
\text { was designed with a steel-reinforced joint (longitudinal reinforcement and stirrups), } \\
\text { the second model performed with (GFRP) -reinforced joint in longitudinal } \\
\text { reinforcement only and the third model performed with (CFRP) -reinforced joint in } \\
\text { longitudinal reinforcement only. The behaviour of the three models under reversed } \\
\text { cyclic loading, their load-storey drift envelope relationship and energy dissipation } \\
\text { capacity were compared. The GFRP-reinforced and CFRP-reinforced models } \\
\text { displayed a predominantly elastic activity up to failure, although the energy } \\
\text { dissipation for GFRP and CFRP models were low, its performance in terms of total } \\
\text { storey drift demand was satisfactory. The GFRP reinforcement's low elasticity } \\
\text { modulus caused a decrease in the overall stiffness of the model at the service stage, } \\
\text { resulting in the obtaining of converging drift ratios and at the same time obtaining } \\
\text { lower forces from its acting earthquake loading. }\end{array}$ \\
\hline
\end{tabular}

\section{INTRODUCTION}

The reinforced concrete structures suffered from corrosion of reinforcing steel problem [1]. Steel corrosion is the main cause of the disintegration of reinforced concrete buildings involving multiple million annual maintenance costs worldwide. This has contributed to increased involvement in FRP reinforcing, as it is a non-magnetic and corrosionresistant material [2]. In the last decade, Important efforts have been made to apply FRP Composite materials to the construction sector and, finally, structural uses of composite materials have started to emerge in civil infrastructure structures. FRP materials used as interior and exterior reinforcements in the field of structural engineering [3]. The high tensile strength, lower density, higher rigidity, chemical resistance, and other properties characterise FRP. FRP can consist of bars, sheets and strips used for reinforcement as well as rehabilitation [4].

In recent years, significant research activities have shown that FRP materials can be used successfully to reinforce RC structures [5,6]. High-tensile fibre stiffeners including aramid, carbon and glass are mixed into polymer arrays and are manufactured in various forms and characteristics such as rods, grids and tubes [3]. FRP reinforcement also offers an opportunity for fast incorporation of optical fiber strain measuring devices of structural health

* Corresponding author. Tel.: +0201211597064.

E-mail address: asmaasobhy1193@gmail.com 
monitoring applications. Even so, FRP Composite materials also show poorer elasticity and lower bonding with concrete compared to traditional steel reinforcement. The bonding of FRP to concrete can be stabilised using mechanical anchorages like surface deformation and sanding, however, its poorer ductility persists a major problem, particularly in structures subject to dynamic loading [2].

BFRP and GFRP have a special mix of high tensile strength and low elasticity between FRP building materials, which can prevent brittle FRPreinforced structures from collapsing during the earthquake. These materials could resist heavy tensile strain leading up to fail due to the comparatively low elastic modulus and the high tensile strength of BFRP and GFRP. This allows the BFRP and GFRPreinforced concrete components to undergo major lateral deformations during the earthquake without displaying a brittle failure [7].

Said A.M, Nehdi M.L [8] studied experimentally the performance of concrete frames reinforced with GFRP bars and stirrups. The case study consisted of two Beam-column joints, one reinforced with steel and the other reinforced with GFRP bars and stirrups. Beam -column connections specimens were exposed to axial load on column and reversal cyclic load applied on the tip of the beam. At the end of the test, the steel joint had $23 \%$ higher total drifts than the GFRP joint. Besides, there was no sudden loss of strength in the GFRP joint. Because of elastic behaviour and low plasticity features of GFRP bars, the resulted envelope showed lower energy dissipated comparing with the Steel joint [8].

Mady and ElSalakawy [9] studied the seismic behaviour of concrete beam-column joints reinforced with glass (G) FRP bars and stirrups. The case study consisted of five full-scale exterior T-shaped beamcolumn joints, which were tested under seismic load. The key parameters analyzed are the longitudinal and transversal reinforcement types and ratios. The study has indicated that the GFRP-reinforced joints could reach a $4.0 \%$ drift ratio without incurring significant damage. It also concluded that increasing the beam reinforcement ratio, while satisfying the strong column-weak beam principle, could improve the ability of the joint to dissipate seismic energy.

Song.S, et al [10] have conducted Cyclic loading experiments on four concrete frames with an axial compression ratio of 0.31 . The seismic behaviour of the concrete frames is compared and studied, including steel reinforcement, CFRP reinforcements and CFRP hybrid reinforcements. The main aims of the study are CFRP strengthened performance in the
0.31 axial compression ratio, energy dissipation, ductility, degradation of strength, stiffness of unloading, residual structural deformation in various reinforcement models. The results of these studies indicated that, compared to the steel frame, the SteelCFRP hybrid frame displayed outstanding postearthquake repair capacity, equivalent hysteretic energy dissipation capability and acceptable strength degradation. [10].

Sharbatdar, et al [11]. investigated the behaviour of three full-scale external beam-column joints reinforced with longitudinal CFRP bars and CFRP grids (as stirrups). Test variables were the spacing of the stirrups inside the joint and the arrangement of the longitudinal reinforcement in the beams and columns. Test specimens obtained a lateral drift ratio of more than $3.0 \%$, while stable elastic behaviour was detected, which means satisfying the strength and ductility (deformability) specifications of earthquake-resistant structures [11].

\section{OBJECTIVE AND SCOPE}

Research towards future design codes of FRP reinforced concrete earthquake fields is required to research the analysis of FRP-RC frames under reversal cyclic loading.

In this research, the ANSYS finite element program [12] used to simulate beam-column joint models reinforced with steel bars, GFRP bars and CFRP bars and analyzed under reversal cyclic loading and Comparison and discussion of their performance, including load-storey drift envelope and energy dissipation.

\section{FINITE ELEMENT ANALYSIS}

The Finite Element Method (FEM) is a numerical method to solve differential or integral equations and also to obtain approximate solutions for a variety of engineering problems. The method is based on assuming the nonlinear function of the solution and gaining the function parameters in a way that decreases the error of the solution [13]. ANSYS is a general-purpose software that used for simulated interactions in all fields of physics, fluid dynamics, structural, heat transfer, vibration and electromagnetic into engineers [14].

In this research, a 3D finite element modelling was conducted using ANSYS 18.2 software. The ANSYS element library includes more than 150 different types of components. Each class of element 
has a unique code and a prefix that describes the category element such as:

- Element SOLID 65 is used for the simulation of concrete. The element contains 8 nodes, with 3 degrees of freedom for each node: the conversions in the nodal directions $\mathrm{x}, \mathrm{y}$, and $\mathrm{z}$. The Solid 65 element can estimate plastic deformation, cracking in 3orthogonal directions, crushing concrete and creep [14].

- Element LINK 180 is used for the modelling of steel and GFRP reinforcement. The element is a uniaxial tension-compression element with 3 degrees of freedom at each node: the conversions in the nodal directions $\mathrm{x}, \mathrm{y}$ and $\mathrm{z}$ [14].

- Element SOLID 185 is used for the simulation of loading and bearing plates. This element is represented in 8 nodes with 3 degrees of freedom at each node; in the nodal directions $\mathrm{x}, \mathrm{y}$, and $\mathrm{z}$. The element is capable of plasticity, hyperelasticity, stiffening of stress, creeping, large deflection and high strain power. SOLID185 is available in two forms, homogeneous and of a solid structural layer [14].

\section{VERIFICATION}

Beam-column joint from literature Tested by Hasaballa. M.H. [15], was studied used numerical analysis via ANSYS software. The dimension of the tested joint as shown fig 1 .

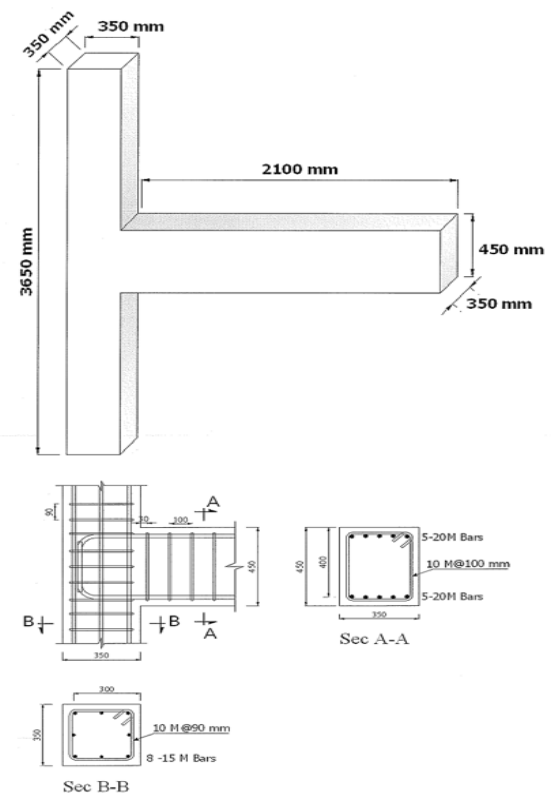

Fig. 1. Details of tested beam-column joint (Hasaballa,) [15]
Reinforced steel for beam (flexural reinforcement of beam $=5-20 \mathrm{M}$ with bar diameter $=19.5 \mathrm{~mm}$ Top and Bottom, Stirrups of the beam =2-10M @ $100 \mathrm{~mm}$ with bar diameter $=11.3 \mathrm{~mm}$ ). The reinforcement steel for the column was (Longitudinal rebar's $=8$ $15 \mathrm{M}$ with bar diameter $=15.9 \mathrm{~mm}$, stirrup $=2-10 \mathrm{M}$ @90 mm). The material properties were, Yield strength $(f y=400 \mathrm{MPa})$ for Steel reinforcement, The concrete compressive strength $(f c=32.4 \mathrm{MPa})$. The joint specimen was loaded under reversed cyclic load, the loading process consisted of two loading phases. The first phase was carried out at a loadcontrolled mode, while the second phase was at a displacement-controlled mode. The cyclic reversed load as seen in Fig 2 has applied to the upper end of the beam, the column head has applied to a constant axial load with a magnitude of $670 \mathrm{kN}$ and remained constant in all loading cycles. The two ends of the column were restrained against both vertical and horizontal displacements meanwhile their rotations were allowed (hinged boundary conditions). The beam-column joint of (Hasaballa,) was modelled by using the ANSYS program as shown in Fig 3 and compared results with experimental results as shown in Fig 4. It can be concluded that analysis using the ANSYS program obtained the same trend of the experimental work results with good accuracy.

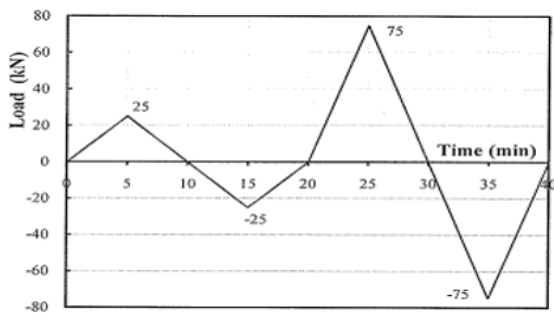

(a) First loading phase - load-controlled mode

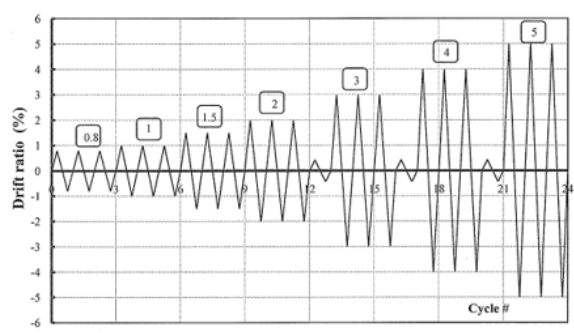

(b) Second loading phase - displacement-controlled mode

Fig. 2. Load history for the reversed cyclic load [15] 

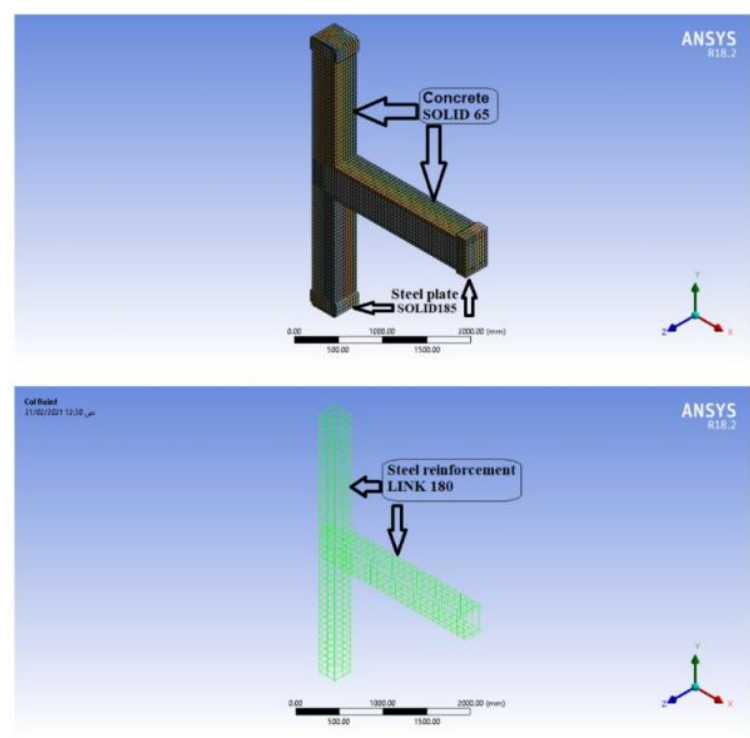

Fig. 3. Finite element model details of studied joint

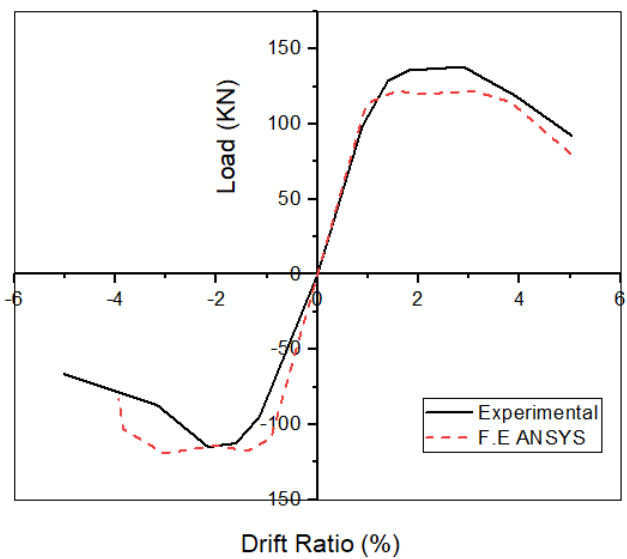

Fig. 4. Load-drift relationship envelops (FE VS Experimental)

\section{NUMERICAL ANALYSIS (ANSYS)}

The non-linear FE analysis program ANSYS [12] was used to model the behaviour of the beam-column joints reinforced with FRP bars under cyclic loading. Beam-column joints are external joint in a multi-story $\mathrm{RC}$ frame. The beam is taken from the center of the bay, although the column is taken from the centre of the height of one storey to the center in the next storey.

\subsection{Model discretization}

The solid element (solid 65) was used to model the concrete. The concrete material is assumed to be initially isotropic, before cracking or crushing. Each element has eight integration points at which cracking and crushing checks are performed. Cracking or crushing occurs once one of the element's principal stresses exceeds the tensile or compressive strength of concrete. Cracked or crushed regions are formed perpendicular to the relevant principal stress direction. Stresses are then redistributed locally. Therefore, the element is nonlinear and requires an iterative solution. A Link 180 element was used to model the steel, GFRP and CFRP reinforcement. Unlike concrete, steel is very uniform and as such generally, the specification of a single stress-strain relation is adequate to define it numerically. The solid element (solid 185) was used to model the loading and bearing plates. Finite element analysis requires meshing of the model; hence the models are divided into many small elements, the maximum chosen mesh dimension was $50 \times 50 \mathrm{~mm}$. Finite element model of beam and column, as shown in Fig (5).

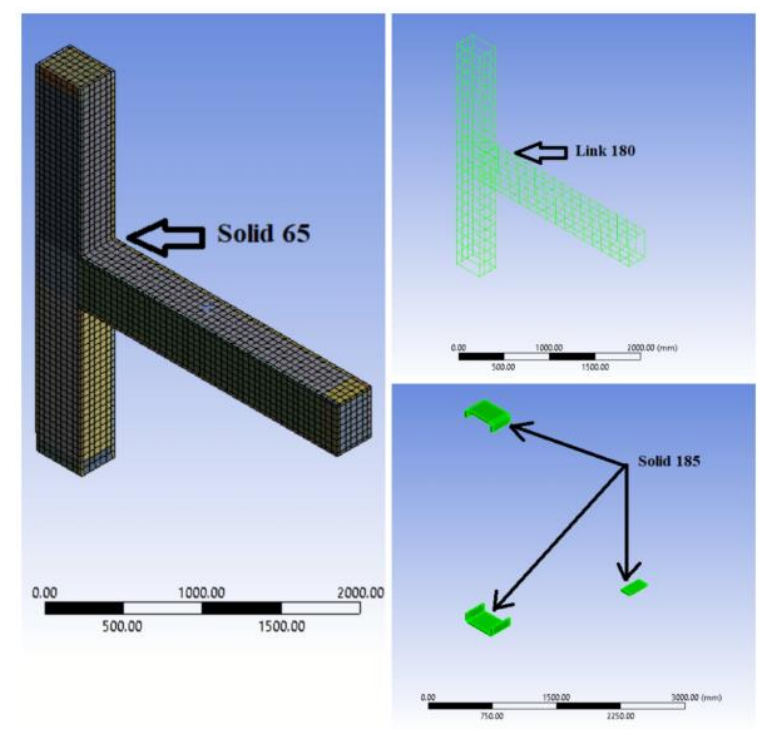

Fig. 5. Finite element model.

The concrete was bounded with reinforcement steel or FRP bars in ANSYS using bonded contact. The concrete was bound to the bearing and bearing plates using node merge to the surface between them. The column ends were restrained to simulate hinge supports at the lower end and roller support at the upper end, as shown in Fig (6). 


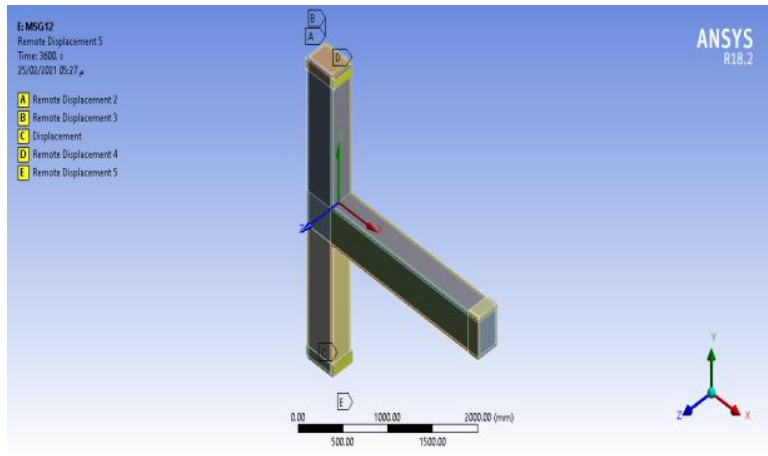

Fig. 6. Boundary conditions.

\subsection{Steel_reinforced model (S1)}

Steel beam-column joint model (S1) is a control model reinforced with conventional steel reinforcement in the longitudinal and transverse directions, designed to satisfy ECP-201 [16] requirements. Reinforcement details as seen in Fig 7.

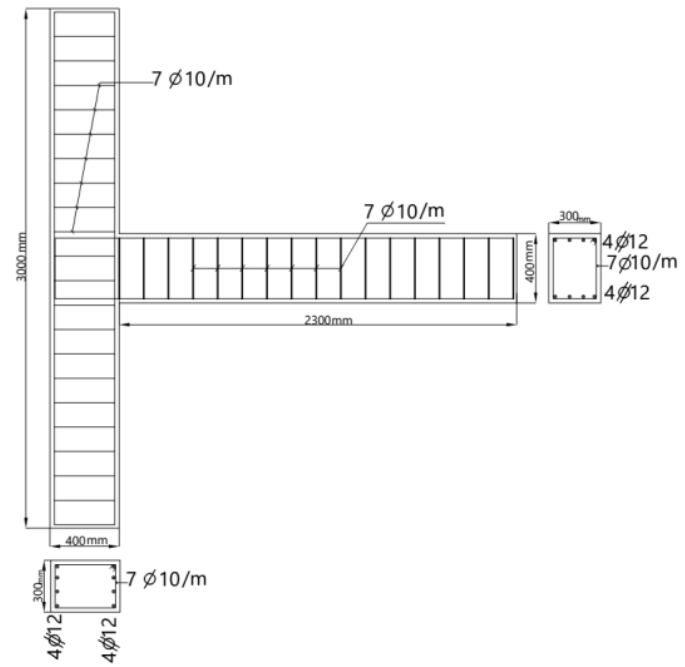

Fig. 7. Reinforcement details for the steel-reinforced model (S1)

\subsection{GFRP_reinforced model (G1)}

GFRP beam-column joint model (G1) had conformable dimensions to model (S1) but was reinforced with GFRP reinforcement. It is reinforced with longitudinal GFRP bars and steel stirrups. Reinforcement details as seen in Fig 8.

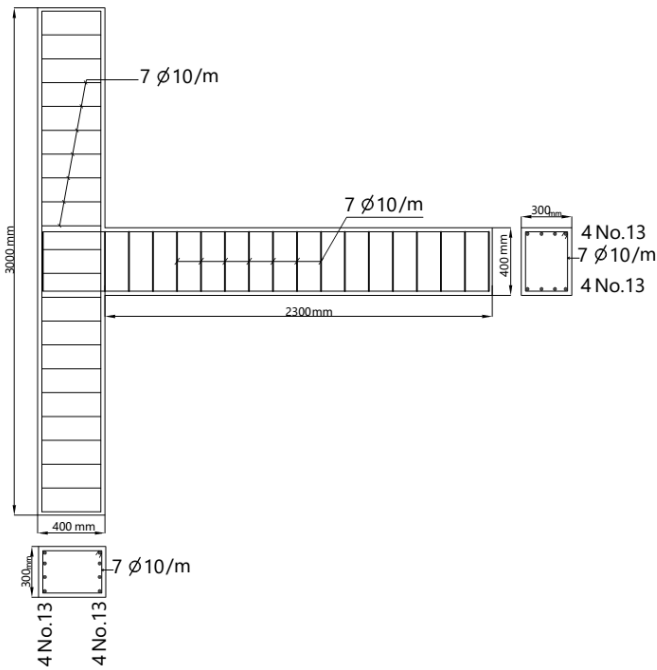

Fig 8. Reinforcement details for the GFRP-reinforced model (G1)

\section{4. $C F R P_{-}$reinforced model $(C 1)$}

The $\mathrm{CFRP}_{-}$reinforced model $(\mathrm{C} 1)$ had identical dimensions to that of the two other models, it is reinforced with longitudinal CFRP bars and steel stirrups. Reinforcement details as seen in Fig 9.

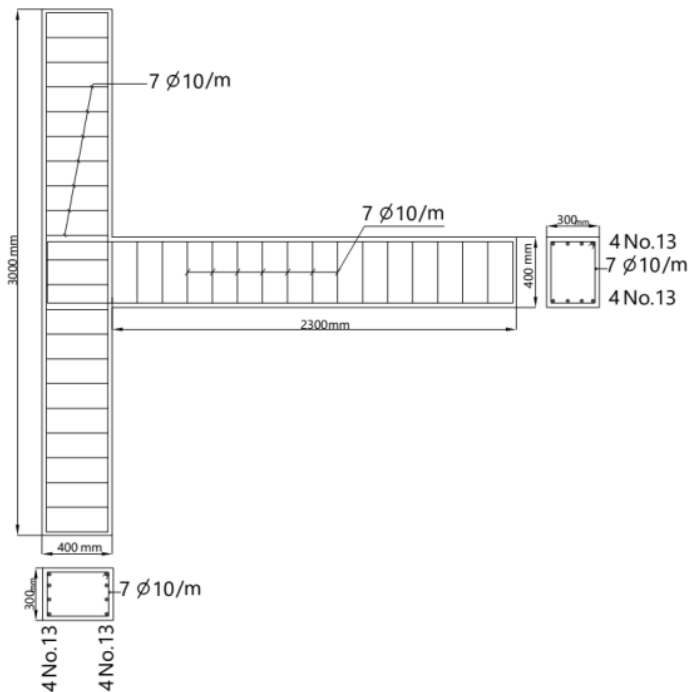

Fig. 9. Reinforcement details for the CFRPreinforced model $(\mathrm{C} 1)$ 


\section{MATERIALS PROPERTIES}

The mechanical properties and plasticity parameters of the materials used in the beam-column joint models according to ECP (201), ECP (208), ISIS Canada and ACI 440.R1.06 [16,17,18,19], are shown in the following table:

Table 1. Mechanical characteristics of concrete, steel reinforcing, GFRP reinforcing and CFRP reinforcing bars materials

\begin{tabular}{|c|c|c|}
\hline Material & Property & Value \\
\hline \multirow{4}{*}{ Concrete } & $\begin{array}{c}\text { Elastic } \\
\text { modulus } \\
\left(E_{c}\right)\end{array}$ & $28125(\mathrm{Mpa})$ \\
\hline & $\begin{array}{l}\text { Poisson's } \\
\text { ratio }(v)\end{array}$ & 0.25 \\
\hline & $\begin{array}{l}\text { Unconfined } \\
\text { compressive } \\
\text { strength }\left(f_{c}\right)\end{array}$ & $30.00(M p a)$ \\
\hline & $\begin{array}{l}\text { Tensile } \\
\text { strength } \\
\quad\left(f_{t}\right)\end{array}$ & $2.91(\mathrm{Mpa})$ \\
\hline \multirow{4}{*}{$\begin{array}{c}\text { Reinforcement } \\
\text { steel }\end{array}$} & $\begin{array}{l}\text { Elastic } \\
\text { modulus } \\
\left(E_{\mathrm{s}}\right)\end{array}$ & $200(G p a)$ \\
\hline & $\begin{array}{l}\text { Poisson's } \\
\text { ratio } \\
(v)\end{array}$ & 0.2 \\
\hline & Yield & Longitudinal \\
\hline & $\begin{array}{l}\text { strength } \\
\left(f_{y}\right)\end{array}$ & $400(M p a)$ \\
\hline \multirow{2}{*}{ GFRP } & $\begin{array}{l}\text { Elastic } \\
\text { modulus } \\
\left(E_{\mathrm{f}}\right)\end{array}$ & $43(G p a)$ \\
\hline & $\begin{array}{l}\text { Ultimate } \\
\text { Strength } \\
\quad\left(f_{\mathrm{fu}}\right)\end{array}$ & $765(M p a)$ \\
\hline \multirow{2}{*}{ CFRP } & $\begin{array}{l}\text { Elastic } \\
\text { modulus } \\
\left(E_{\mathrm{f}}\right)\end{array}$ & $147(G p a)$ \\
\hline & $\begin{array}{l}\text { Ultimate } \\
\text { Strength } \\
\quad\left(f_{\mathrm{fu}}\right)\end{array}$ & $2255(M p a)$ \\
\hline
\end{tabular}

\section{LOAD PROTOCOL}

Beam-column joint models have been analyzed under reversed cyclic load. The cyclic reversed load as seen in Fig 10 has applied to the upper end of the beam, the column head has applied to a constant axial load with a magnitude of $140 \mathrm{kN}$ and remained constant in all loading cycles [20]. Fig 11 illustrates the applied loads on the model

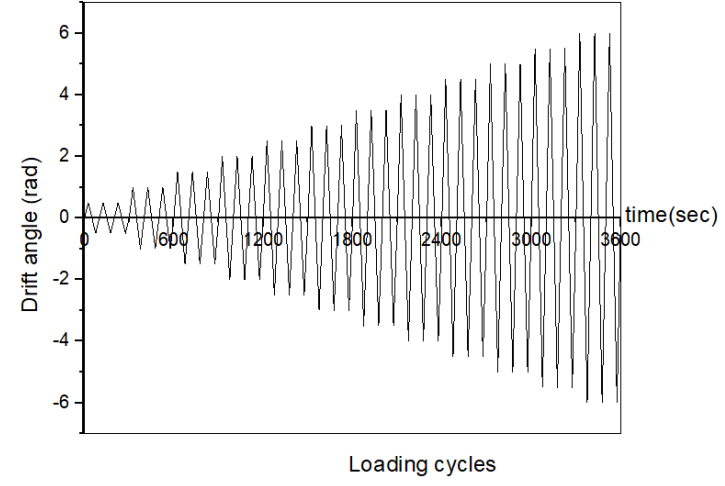

Fig.10. Load history for the reversed cyclic load [20]

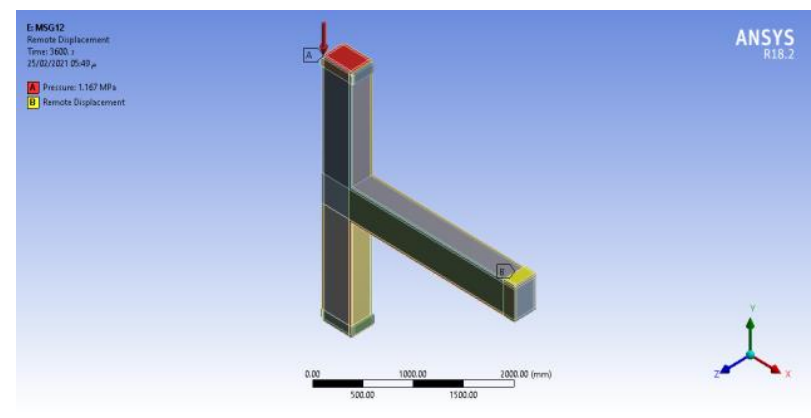

Fig.11. The applied loads on the model

\section{ANALYSIS AND DISCUSSION}

\subsection{Steel-Reinforced Model (S1)}

The hysteretic diagram for the steel-reinforced model S1 is shown in Fig 12. The hysteretic diagram shows that the model reached the drift ratio that (5.35\% drift ratio) with a corresponding load capacity of $51 \mathrm{kN}$ in the positive direction and reached $(5.00 \%$ drift ratio) with a corresponding load capacity of $38.35 \mathrm{kN}$ in the negative direction. The maximum capacities observed were at $6 \%$ and $5 \%$ drift ratios in both the positive and negative direction, respectively. The reason behind this that after completing the $4.5 \%$ drift ratio-seismic step, the model failed at a 5\% drift ratio in the negative direction. The program stopped immediately without have completed the 5\% drift ratio loop. 


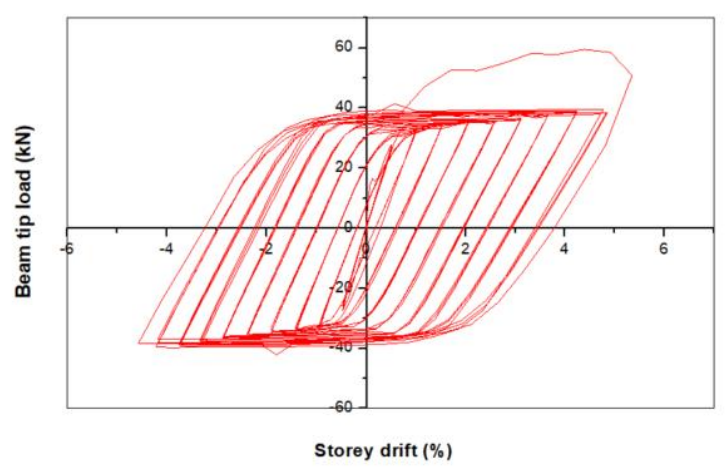

Fig.12. Load-storey drift relationship of the steel model (S1).

Failure mode was the cracking of the concrete in the sections of the beam near the face of the column as seen in Fig 13.

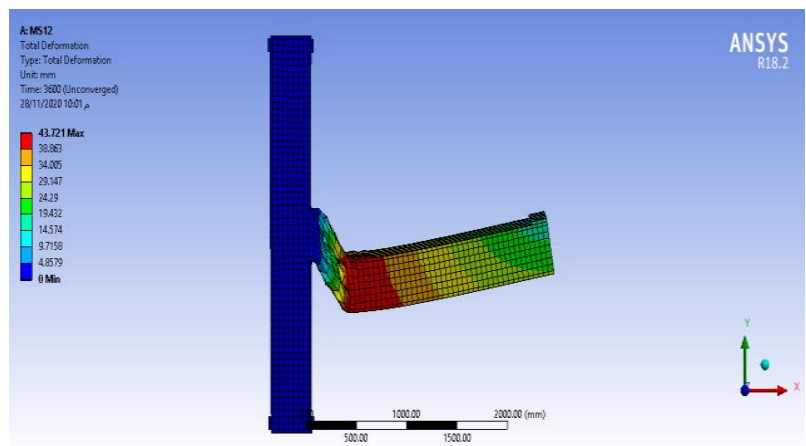

Fig.13. Total deformation for the steel-reinforced model (S1)

\subsection{GFRP-Reinforced Model (G1)}

The hysteretic diagram for the GFRP-reinforced model (G1) is as seen in Fig 14. The model demonstrated linear elastic performance until failure. The hysteretic diagram shows that the model kept carrying capacity till failure started at the drift ratio ( $4.21 \%$ drift ratio) with a corresponding load capacity of $44.7 \mathrm{kN}$. The maximum capacities observed were at $4.21 \%$ and $3.19 \%$ drift ratios in both the positive and negative direction, respectively. The reason behind this that after completing the $3.5 \%$ drift ratioseismic step, the model failed at a $4 \%$ drift ratio in the negative direction. The program stopped immediately without completing the cycle of the $4 \%$ drift ratio.

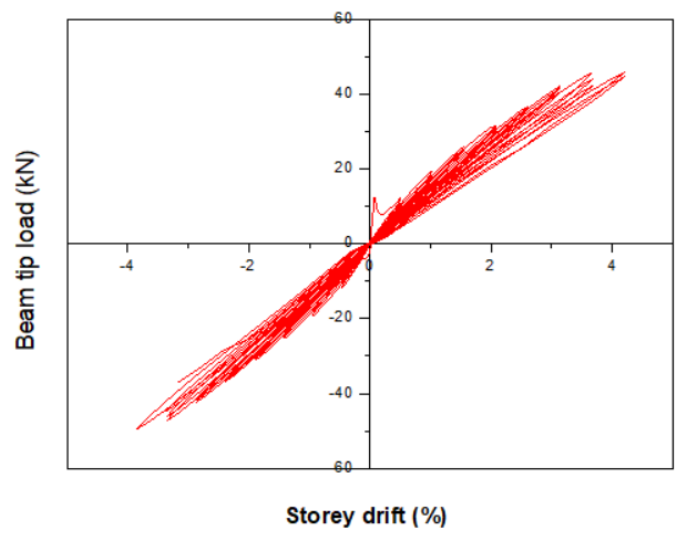

Fig.14. Load-storey drift relationship for the GFRP- model (G1).

Failure mode was the cracking of the concrete in the sections of the beam close to the face of the column and diagonal shear cracks appeared in the joint area as seen in Fig 15.

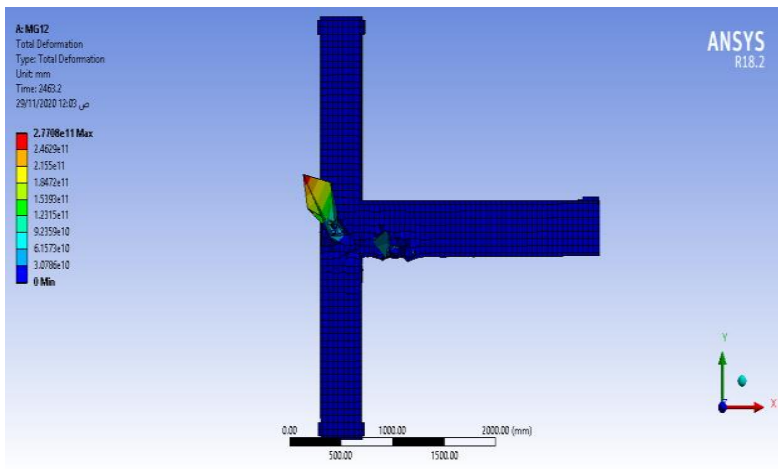

Fig.15. Total deformation for the GFRP-reinforced model (G1)

\subsection{CFRP-Reinforced Model (C1)}

The hysteretic diagram for the CFRP-reinforced model (C1) is as seen in Fig 16. The model showed linear elastic behaviour till failure occurred. The hysteretic diagram shows that the model kept carrying capacity till failure started at the drift ratio (2.95\% drift ratio) with a corresponding load capacity of $60.79 \mathrm{kN}$. The maximum capacities observed were at $2.95 \%$ and $2.38 \%$ drift ratios in both the positive and negative direction, respectively. The reason behind this that after completing the $2.5 \%$ drift ratio-seismic step, the model failed at a $3 \%$ drift ratio in the positive direction. The program stopped 
immediately without completing the cycle of the $3 \%$ drift ratio.

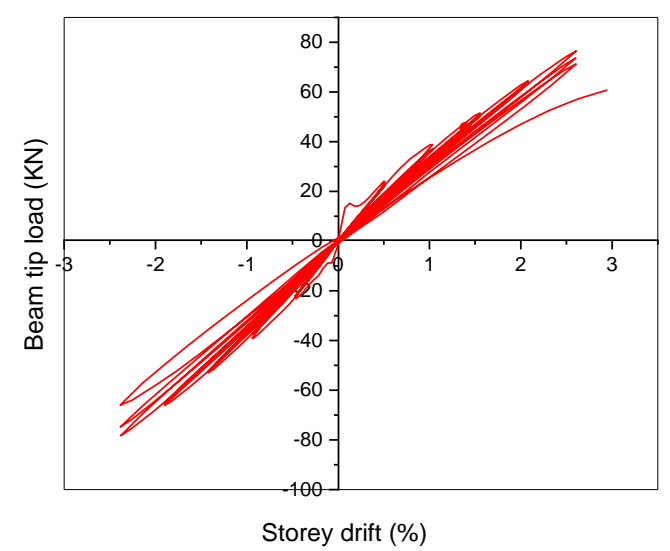

Fig.16. Load-storey drift relationship of the CFRP model (C1).

Failure mode was the cracking of the concrete in diagonal shear cracks that appeared in the joint area as seen in Fig 17.

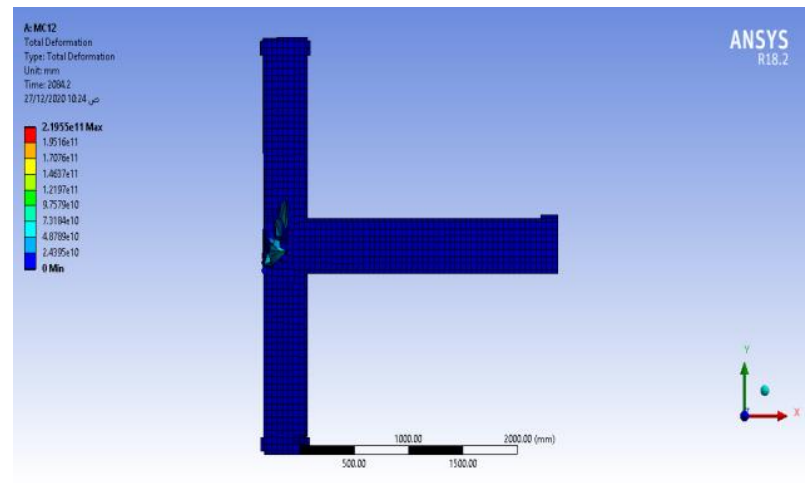

Fig.17. Total deformation for the CFRP-reinforced model (C1).

\subsection{Load - Storey Drift Angle Envelope Relationship}

A comparison of load-storey drift relationship envelopes for all models is shown in Fig 18. Envelopes began at comparable stiffness, however, once cracking occurs a distinguished variation between the performance for all models have shown. Comparison between the three envelopes displayed, The GFRP-reinforced model showed reduced stiffness, that is due to the poorer stiffness of GFRP compared to steel and CFRP. The total drift of the GFRP model (G1) was about $20 \%$ lower than that of the steel model (S1) and was $23 \%$ higher than that of the CFRP model (C1) in terms of total drift. The steel model is capable of achieving a much more constant post-yield load capability compared with the other models, so it has a typical elastic-plastic envelope. The GFRP and CFRP models have an elastic envelope. These results were consistent with previous experimental literature, such as Said A.M, Nehdi M.L [8], Mady and ElSalakawy [9] and Sharbatdar, et al [11]. Said A.M, Nehdi M.L [8] concluded that the steel joint had 23\% higher total drifts than the GFRP joint. Mady and ElSalakawy [9] concluded that the low elasticity modulus for GFRP reinforcement decreased the rigidity of the specimens tested, resulting in lower forces attracting from the acting drifts. Sharbatdar, et al [11] concluded that the CFRP joints obtained a lateral drift ratio of more than 3.0 $\%$, while stable elastic behaviour was detected [11].

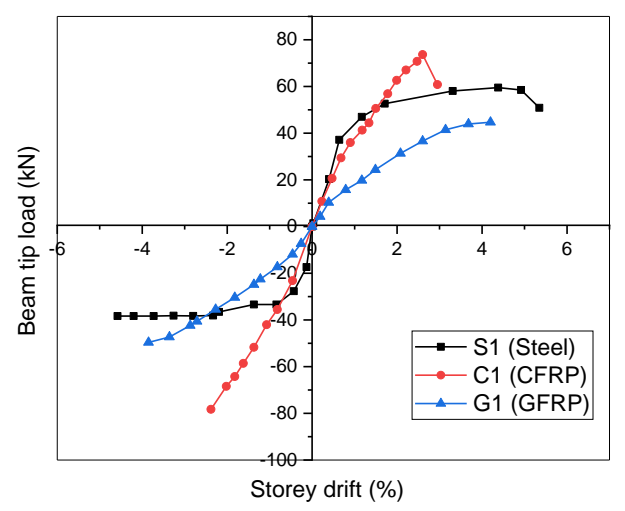

Fig.18. Comparison of load-storey drift relationship envelopes for all models.

\subsection{Cumulative Dissipated Energy}

The capacity of the earthquake resistance of the structures to dissipate the energy input relies on the ground movement. Although the measurement of this energy input through the ground movement of the event is difficult, an appropriate design must ensure that the system has a higher energy dissipation capacity than the demand. Cumulative energy dissipated was calculated in successive loaddisplacement cycles by summing the energy dissipated during the reverse cyclic load analysis. The energy dissipated during the cycle is measured as the region occupied by the hysteric loop in the loaddisplacement graph.

Fig 19 displays cumulative energy dissipation plots and storey drift for the models analyzed. Fig 19 
shows that the GFRP model (G1) has around $2.5 \%$ of the standard steel model (S1) energy dissipation capacity before failure. The CFRP model (C1) had about $1.04 \%$ of the standard steel model (S1) energy's dissipation capacity before failure. The cumulative energy dissipation capacity of the GFRP model (G1) was around 2 times greater at failure than the CFRP model (C1). This is apparent from the form of the individual hysteretic loops of the calculated models' Figs (12,14 and 16), which are much wider for the steel model. The steel reinforcement's ductility resulted in the beam creating more plastic deformations, increasing the area of each loop. The amount of damage suffered by the models during failure, as seen in Fig. (13,15 and 17), indicates that while the significant crack in the beam hinge region allowed the steel model to dissipate energy, the GFRP and CFRP models suffered serious although localized destruction. Steel yield has become a significant technique for the dissipation of energy by RC structures, while plastic deformations and friction around concrete cracks typically have a lower contribution to the dissipation of total energy. These results were consistent with previous experimental literature, such as Said A.M, Nehdi M.L [8], Mady and ElSalakawy [9] and Sharbatdar, et al [11]. Said A.M, Nehdi M.L [8] concluded that GFRP specimens had about $25 \%$ of the standard steel specimen's energy dissipation before failure. Mady and ElSalakawy [9] concluded that steel-reinforced specimen absorbed energy is much greater than that of the GFRP reinforced specimens.

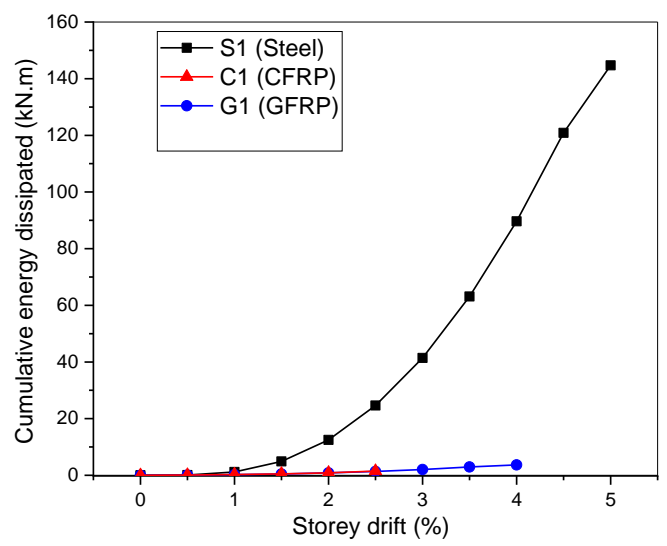

Fig.19.Cumulative energy dissipated for the models.

\section{CONCLUSIONS}

This research was conducted to investigate the performance of beam-column-reinforced joints using
GFRP and CFRP-reinforced in longitudinal reinforcement and steel stirrups and to compare them with conventional steel-reinforced joints under reversal cyclic load. Based on the study of the finite element using ANSYS software and the analysis of the results, the following conclusions are drawn:

1. In beam-column joints exposed to cyclic loading, GFRP and CFRP bars may be used as longitudinal reinforcing. GFRP and CFRP bars without any performance degradation can withstand tensioncompression cycles.

2. The GFRP reinforced beam-column joint amounted to $4.0 \%$ drift capacity safely with measly damage. The GFRP-reinforced joint can be designed to satisfy both the strength and ductility requirements of earthquake-resistant structures.

3. The total drift of the GFRP model (G1) was about $20 \%$ lower than that of the steel model (S1) and was $23 \%$ higher than that of the CFRP model (C1) in terms of total drift.

4. The low elasticity modulus of the GFRP reinforcement caused a drop in the overall stiffness of this model in operation, resulting in the converging drift ratios being obtained, though at the same time obtaining lower forces due to cyclic loading.

5. GFRP-reinforced joint model (G1) and the CFRPreinforced joint model $(\mathrm{C} 1)$ have around $2.5 \%$ and $1.04 \%$ of the standard steel model (S1) energy dissipation capacity before failure respectively.

6. GFRP and CFRP-reinforced joints exhibited mainly elastic behaviour with very poor plasticity characteristics when analyzed under reversed cyclic load. This resulted in decreased energy dissipation contrasted to traditional steel-reinforced joints.

7. The cumulative dissipation capacity of the GFRPreinforced joint at failure was around 2 times that of the CFRP-reinforced joint.

\section{References}

[1] A. S. Shanour, M. A. Adam, A. A. Mahmoud, and M. Said, "Experimental Investigation of Concrete Beams Reinforced With GFRP Bars.", International Journal of Civil Engineering and Technology.Vol.5, Issue 11, pp. 154-164, November 2014.

[2] A. M. Said and M. L. Nehdi, "Performance of Structural Concrete Frames Reinforced with GFRP Grid," 13th World Conf. Earthq. Eng., 2004.

[3] M. Abedini, E. Akhlaghi, J. Mehrmashhadi, M. H. Mussa, M. Ansari, and T. Momeni, "Evaluation of Concrete Structures Reinforced with Fiber Reinforced Polymers Bars: A Review," J. Asian Sci. Res., vol. 7, no. 5, pp. 165-175, 2017, doi: 10.18488/journal.2.2017.75.165.175.

[4] S. M. M. Mogahed, "Seismic Evaluation of Framed Structures Reinforced with FRP Bars", Master Thesis, 
Department of Structural Engineering, Zagazig University, 2019.

[5] J. F. Davalos, Y. Chen, and I. Ray, "Effect of FRP bar degradation on interface bond with high strength concrete," Cement and Concrete Composites, vol. 30, pp. 722-730, 2008.

[6] M. I. Alam, S. Fawzia, and X. Liu, "Effect of bond length on the behaviour of CFRP strengthened concrete-filled steel tubes under transverse impact," Composite Structures, vol. 132, pp. 898-914, 2015.

[7] S. K. Ghomi, and E. El-Salakawy, "Effect of Joint Shear Stress on Seismic Behaviour of Interior GFRP-RC BeamColumn Joints", Engineering Structures, Volume 191, Pages 583-597, ISSN 0141-0296,2019.

[8] A. M. Said, and M. L. Nehdi, "Use of FRP for RC frames in seismic zones: part II. Performance of steel-free GFRPreinforced beam-column joints. " Appl Compos Mater; 11:227-45, 2004.

[9] M. Mady, A. El-Ragaby, and E. El-Salakawy, "Seismic behavior of beam-column joints reinforced with GFRP bars and stirrups. " J Compos Constr, ASCE;15(6):875-86, 2011.

[10] S. Song, G. Wang, X. Min, N. Duan, and Y. Tu, " Experimental study on cyclic response of concrete frames reinforced by Steel-CFRP hybrid reinforcement", Journal of Building Engineering, Volume 34, 101937, ISSN 2352-7102, 2021, https://doi.org/10.1016/j.jobe.2020.101937.

[11] M. K. Sharbatdar, M. Saatcioglu, B. Benmokrane, and E. ElSalakawy, "Behaviour of FRP reinforced concrete beamcolumn joints under cyclic loading. ", In 3rd International Conference on Durability \& Field Applications of Fibre Rein-forced Polymer (FRP) Composites for Construction, (CDCC-07), Quebec City, Quebec, Canada (pp. 541-548), (2007).

[12] Ansys Workbench, Version 18.2.

[13] M. R. Abdulkadir, Z. A. Aziz, and J. H. Muhammad, " Nonlinear Finite Element Analysis of Reinforced Concrete Beams Strengthened with Externally Bonded Steel Plate using ANSYS " Sulaimani Journal for Engineering Sciences / Volume 4 - Number 4-2017.

[14] ANSYS, Inc., "ANSYS Mechanical APDL Theory Reference", Release 14.5, 2013.

[15] M. H. Hasaballa, " Seismic Behaviour of Exterior GFRPReinforced Concrete Beam-Column Joints ", Master Thesis, Department of Civil Engineering, Manitoba University, (2009).

[16] ECP-201, (2018), "Egyptian code for design and constructions concrete structures ", housing and building national search centre. ministry of housing, utilities and urban planning, Cairo.

[17] ECP208, (2005), " The Use of Fiber Reinforced Polymer (FRP) In The Construction Fields ", Egyptian Code of Practice.

[18] ISIS Canada., (2007). "Reinforcing Concrete Structures with Fibre Reinforced Polymers - Design Manual 3", ISIS Canada Corporation, University of Manitoba, Winnipeg, Canada.

[19] ACI Committee 440, "Guide for the Design and Construction of Structural Concrete Reinforced with FRP Bars", (ACI 440.1R-06), American Concrete Institute, Farmington Hills, MI.

[20] A. H. Paknejadi and K. Behfarnia, "Performance of reinforced self-consolidating concrete beam-column joints with headed bars subjected to pseudo-static cyclic loading", Ain Shams Engineering Journal, Volume 11, Issue 3, 2020, Pages 751-765, ISSN 2090-4479, https://doi.org/10.1016/j.asej.2019.12.008. 